CLINICAL STUDY

\title{
Ghrelin and acyl ghrelin in preterm infants and maternal blood: relationship with endocrine and anthropometric measures
}

\author{
Éva Lányi, Ákos Várnagy ${ }^{1}$, Kálmán A Kovács ${ }^{1}$, Tamás Csermely ${ }^{1}$, Mária Szász ${ }^{2}$ and István Szabó ${ }^{1}$ \\ Department of Laboratory Medicine, Medical School, University of Pécs, 7624 Pécs József Au. 7. Pécs, Hungary, Departments of ${ }^{1}$ Obstetrics and \\ Gynecology and ${ }^{2}$ Pediatrics, Medical School, University of Pécs, Pécs, Hungary
}

(Correspondence should be addressed to É Lányi; Email: eva.lanyi@aok.pte.hu)

\begin{abstract}
Objective: The objective of the present study was to examine the association of acylated and total ghrelin levels at birth in preterm infants with anthropometric features and with related hormones in infants and their mothers.

Design: Prospective, descriptive study.

Methods: In total 23 pregnant women and their 26 preterm infants were involved in the study ( 3 twin pregnancies; gestational age, 25-35 weeks). Maternal and umbilical vein blood samples were taken after the delivery. Serum acylated and total ghrelin, leptin, cortisol, insulin, GH, and glucose were determined. Results: The mean level of acylated ghrelin concentration was higher in the maternal than in the cord blood $(P<0.01)$ and there was a significant correlation between the fetal and maternal acylated ghrelin levels $(P<0.01)$. The total ghrelin concentration was higher in neonates than in mothers $(P<0.01)$, but there was no correlation between them. The multivariate regression analysis for fetal acylated and maternal total ghrelin as dependent variables shows that the fetal acylated ghrelin has two independent predictors, the maternal acylated ghrelin $(P<0.01)$ and the fetal cortisol $(P<0.05)$, whereas the maternal total ghrelin has only one independent predictor, the maternal glucose $(P<0.05)$.

Conclusions: These data provide the first evidence that umbilical cord acylated ghrelin concentrations are lower than in maternal blood and support the hypothesis that the acylation process in the fetus is partly affected by cortisol and the placenta may play a role in this process.

European Journal of Endocrinology 158 27-33
\end{abstract}

\section{Introduction}

Ghrelin is the first known peptide that requires posttranslational $n$-octanoyl modification of a Serine 3 residue for its biological activity (1). Due to the fatty acid attached to Serine 3, acylated ghrelin is unstable and easily changes to the des-octanoylated form during sample collection (2). This makes it difficult to evaluate the significance of the acylation under physiological conditions. It is known that only the octanoylated ghrelin is able to stimulate growth hormone (GH) secretion (3), but the role of acylated and des-acylated ghrelin in glucose metabolism and body mass remains mostly unknown (4).

This peptide is produced predominantly by the stomach (5), whereas lower amounts are derived from the hypothalamus, kidney, heart, pancreatic cells, and the placenta in humans (6). The presence of significant ghrelin concentrations in human cord blood has been shown (7) but information about the ghrelin secretion during fetal life is scarce. The source of ghrelin on cord plasma is unknown; it may have originated from the maternal compartment, may be secreted by the placenta, or may come directly from the fetal tissues $(8,9)$.
The available data are not consistent; associations among circulating ghrelin levels and anthropometric and hormonal parameters have been reported by some authors but not by others $(10,11)$. In adults, the ghrelin stimulates $\mathrm{GH}$ release from the pituitary and GH-releasing hormone (GHRH) from the hypothalamus through the GH secretagogue receptor (GHS-R), and this function is associated only with the acylated form of ghrelin (12). The GH hypersecretory state during the fetal period is known (13) and there is a possibility that acylated ghrelin plays a role in somatotroph hypersecretion during gestation.

It is not known whether ghrelin, in des-acylated or acylated form, plays a role in energy homeostasis during fetal life. Ghrelin has both orexigenic and adipogenic effects $(14,15)$ and there is a negative correlation between total ghrelin and body mass index, insulin, and leptin in lean and obese Whites and Pima Indians (16). Concentration of total ghrelin in cord blood of small-forgestational age infants were significantly greater than in appropriate-for-gestational age at different times of gestation $(9,17)$. A similar relationship has been observed in adults, where patients with anorexia nervosa had higher total ghrelin concentrations than controls (18). 
It is known that the hypercortisolism in humans decreases total ghrelin levels in plasma (19) and that serum cortisol exhibits a negative correlation with total ghrelin (20). The physiological mechanisms behind this relationship are not known, but the glucocorticoids that are used in antenatal therapeutic settings may have an effect on ghrelin secretion.

During pregnancy, the high GH levels may be related to the acylated ghrelin in the fetus, and the total ghrelin may be implicated in the control of metabolism. The point of the present study was to compare acylated and total ghrelin concentration in premature infants and their mothers and to investigate the possible relationship between ghrelin and anthropometric and hormonal parameters, such as leptin, insulin, GH, and cortisol.

\section{Subjects and methods}

\section{Subjects}

The 26 preterm infants (15 males and 11 females, gestational age 25-35 weeks) born in the Department of Obstetrics and Gynecology, Faculty of Medicine, University of Pécs and their mothers were involved in the study. All mothers gave written informed consent as required by the local human ethics committee. The gestational age at delivery was calculated from the last menstrual cycle in weeks and reflected the number of completed weeks. Three women with twin pregnancies were included into the protocol together with their newborns. Cesarean section was used for eight mothers. Mothers with pre-eclampsia, hypertension, or diabetes were excluded. The infants and their placentas were weighed immediately after birth. The infants who were appropriate for gestational age participated in this study. It was defined as birth weight from -1.5 to +1.5 s.D. of the mean birth weight in each gestational age according to current Hungarian standard. The birth weight $z$-score was calculated as: (birth weight - the mean of the population)/s.D. of the population. All mothers received betamethasone (12 mg intramuscularly twice at $12-\mathrm{h}$ intervals) because of the Hungarian protocol for the prevention of respiratory distress syndrome. The time interval between the steroid injection and the birth varied from $10 \mathrm{~h}$ to 7 days. Immediately after delivery, a venous cord blood sample was collected from newborns and also from mothers. The tubes containing EDTA $(1 \mathrm{~g} / \mathrm{l})$ with aprotinin $(250 \mathrm{kU} / \mathrm{l})$ were kept at $4{ }^{\circ} \mathrm{C}$ before centrifugation and were centrifuged within $1 \mathrm{~h}$. The plasma samples were stored at $-70^{\circ} \mathrm{C}$ without acidification until they were assayed $(2,21)$.

\section{Ghrelin and other hormone assays}

Acylated ghrelin levels $(\mathrm{pg} / \mathrm{ml})$ were measured by a commercially available RIA kit (Linco Research Inc., St Charles, MO, USA) using antibody specific for ghrelin with the octanoyl group on Serine3. The intra- and interassay coefficients of variations (CVs) were 6.5-9.5 and $9.6-16.2 \%$ respectively. The assay sensitivity was $7.8 \mathrm{pg} / \mathrm{ml}$; the specificity was $100 \%$ for acylated ghrelin and ghrelin 1-10 and $<0.1 \%$ for des-acyl ghrelin and ghrelin 14-28.

Total ghrelin levels $(\mathrm{pg} / \mathrm{ml})$ were measured by commercial RIA kit (Linco Research Inc.) using an antibody that does not require the presence of the octanoyl group on Serine3. The intra- and interassay CVs were $3.3-10.0$ and $14.7-17.8 \%$ respectively. The assay sensitivity was $93 \mathrm{pg} / \mathrm{ml}$; the specificity was $100 \%$ for des-acyl ghrelin and ghrelin 14-28, and ghrelin 1-10 was not detectable.

Leptin $(\mathrm{ng} / \mathrm{ml}$ ) was measured by RIA using a commercially available kit (Linco Research Inc). Sensitivity was $0.5 \mathrm{ng} / \mathrm{ml}$ and intra- and interassay CVs were $3.4-8.3$ and $3.0-6.2 \%$ respectively.

Cortisol $(\mathrm{nmol} / \mathrm{l})$, insulin $(\mathrm{mU} / \mathrm{l})$, and $\mathrm{GH}(\mu \mathrm{g} / \mathrm{l})$ were assayed using commercially available RIA and IRMA kits (Isotope Inst. Kft, Budapest, Hungary). The sensitivity for cortisol was $4.6 \mathrm{nmol} / \mathrm{l}$; the specificity was $100 \%$ for cortisol and $<0.01 \%$ for betamethasone; and intra- and interassay CVs were 5.2-8.8 and $5.2-10.8 \%$ respectively.

Sensitivity for insulin was $5 \mathrm{mU} / \mathrm{l}$, and the intra- and interassay CVs were $5.7-7.1$ and $6.0-10.1 \%$ respectively. Sensitivity for $\mathrm{GH}$ was $0.01 \mu \mathrm{g} / \mathrm{l}$; the specificity was $100 \%$ for $\mathrm{GH}$ and $0.2 \%$ for prolactin; the intra- and inter-assay CVs were $2.1-6.2$ and $4.5-6.7 \%$ respectively. Glucose was measured by the glucose hexokinase method using the Vitalab Selectra-2 system (Merck).

\section{Statistical analysis}

Data were presented as mean \pm s.D. Comparative analyses between maternal and fetal data were calculated by Mann-Whitney test. The correlations between the various study hormones and anthropometric data were analyzed by Spearman correlation analysis. To verify the influence of different variables on fetal or maternal ghrelin levels, we used stepwise multiple regression analysis to determine the effect of independent variables on ghrelin. The model was created using stepwise method, starting from all variables with a significant univariate correlation with any of the indices. Statistical analyses were performed with SPSS 11.5 (SPSS Inc., Chicago, IL, USA) software. $P<0.05$ was considered statistically significant.

\section{Results}

\section{Anthropometric data and hormonal parameters}

Anthropometric data of the neonates are described in Table 1. No significant correlation was observed 
Table 1 Clinical data.

\begin{tabular}{llcc}
\hline & \multicolumn{1}{c}{$\boldsymbol{n}$} & Mean \pm s.D. & Range \\
\hline Male/female & $15 / 11$ & & \\
Singleton/twin & $20 / 3$ & & \\
Cesarean section & 8 & & \\
Gestational age (wk) & 26 & $30.8 \pm 2.4$ & $25-35$ \\
Birth weight (g) & 26 & $1676.2 \pm 534.9$ & $570-2380$ \\
Birth weight $z$-score & 26 & $0.22 \pm 0.37$ & $-0.75-1.07$ \\
Placental weight (g) & 23 & $436.2 \pm 109.1$ & $250-580$ \\
\hline
\end{tabular}

$n$, number of cases; birth weight $z$-score: (birth weight - the mean of the population)/s.D. of the population.

between sex, mode of birth, gestational age, birth weight, birth weight $z$-score, and maternal or fetal acylated and total ghrelin, cortisol, insulin, and leptin levels (data are not shown). There was a significant correlation (Table 3) between placental weight and acylated ghrelin levels of neonates $(r=0.396$, $P=0.045)$ and between placental weight and $\mathrm{GH}$ levels of neonates $(r=0.483, P=0.008)$.

\section{Maternal and fetal hormonal parameters}

Table 2 shows the maternal and fetal concentrations of ghrelin, cortisol, insulin, glucose, leptin, and GHs. The acylated and total ghrelin were detectable in all samples. The mean level of acylated ghrelin concentration was higher in the maternal vein than in the cord vein $(73.1 \pm 33.1$ vs $36.5 \pm 14.6 \mathrm{pg} / \mathrm{ml}, P<0.01)$. Overall, there was a significant correlation (Fig. 1) between the fetal and maternal acylated ghrelin levels ( $r=0.771, P=0.001)$. The total ghrelin concentration was higher in the neonates, than in the mothers $(611.9 \pm 183.2$ vs $295.9 \pm 41.3 \mathrm{pg} / \mathrm{ml}, P<0.01)$, but no significant correlation between the fetal and maternal total ghrelin levels was found.

\section{Correlations among the various hormonal parameters}

The bivariate correlations of cord vein hormones (Table 3) show a significant correlation between the cord vein acylated ghrelin and cord vein cortisol levels

Table 2 Maternal and fetal concentrations of ghrelin, cortisol, insulin, glucose, leptin, and growth hormone $(G H)$.

\begin{tabular}{lcc}
\hline & Maternal $(n=23)$ & Fetal $(n=26)$ \\
\hline Acylated ghrelin $(\mathrm{pg} / \mathrm{ml})$ & $73.1 \pm 33.1$ & $36.5 \pm 14.6^{*}$ \\
Total ghrelin $(\mathrm{pg} / \mathrm{ml})$ & $295.9 \pm 41.3$ & $611.9 \pm 183.2^{*}$ \\
Cortisol $(\mathrm{nmol} / \mathrm{l})$ & $1082.6 \pm 528.8$ & $174.1 \pm 74.6^{*}$ \\
Insulin $(\mathrm{mU} / \mathrm{l})$ & $44.2 \pm 43.5$ & $15.4 \pm 15.6^{*}$ \\
Glucose $(\mathrm{mmol} / \mathrm{l})$ & $7.4 \pm 2.3$ & $5.6 \pm 1.2^{*}$ \\
Leptin $(\mathrm{ng} / \mathrm{ml})$ & $28.9 \pm 13.3$ & $0.86 \pm 0.76^{*}$ \\
GH $(\mu \mathrm{g} / \mathrm{l})$ & $2.6 \pm 3.8$ & $60.2 \pm 33.2^{*}$ \\
\hline
\end{tabular}

All data are presented as means \pm s.D.; $n$, number of cases; ${ }^{\star} P<0.01$ versus mother with Mann-Whitney test.
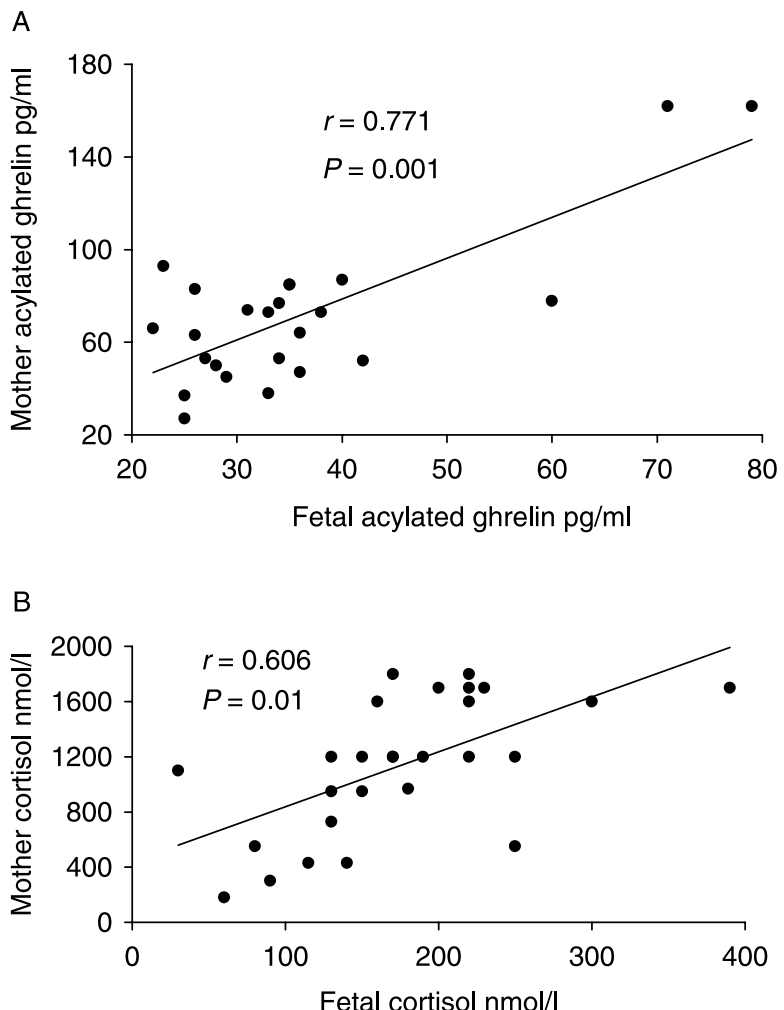

Figure 1 Correlation between paired maternal and fetal plasma acylated ghrelin (A) and cortisol (B) concentration.

( $r=0.547, P=0.005)$. Total and acylated ghrelin levels in the cord vein were unrelated to other studied hormones in the fetuses. The bivariate correlations of mother vein hormones (Table 4) show a negative correlation between the total ghrelin and glucose $(r=-0.577, P=0.003)$ and between the total ghrelin and insulin $(r=-0.510, P=0.008)$. Acylated ghrelin levels in the mothers were unrelated to the studied hormones. Figure 1 shows the significant univariate correlations between mothers and their fetuses in the case of acylated ghrelin $(r=0.771, P=0.001)$ and the cortisol levels $(r=0.606, P=0.01)$. The correlation between maternal and fetal cortisol concentrations remained significant after correction for the number of hours since the last injection of betamethasone (data are not shown).

\section{Multivariate regression analysis}

Table 5 presents a summary of the stepwise multivariate regression analysis for fetal acylated ghrelin and maternal total ghrelin as dependent variables and the placental weight, maternal acylated ghrelin, fetal cortisol and the maternal glucose, maternal insulin, fetal glucose as independent variables. The adjusted $R^{2}$ was 0.639 in the case of fetal acylated ghrelin with maternal acylated ghrelin $(\beta=0.733, P=0.0001)$ and with the fetal cortisol $(\beta=0.286, P=0.038)$, the 


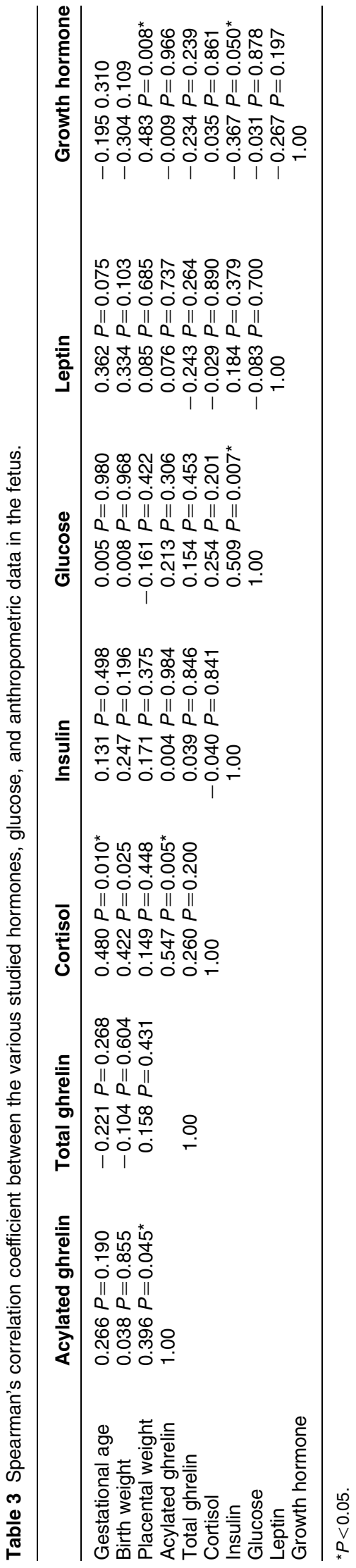

variables have statistically significant correlations with the fetal acylated ghrelin. The adjusted $R^{2}$ was 0.184 in the case of maternal total ghrelin with maternal glucose ( $\beta=0.467, P=0.019$ ), the only variable with statistically significant correlation with maternal total ghrelin. There was no independent predictor when the maternal acyl ghrelin or fetal total ghrelin were used as dependent variables (data are not shown).

\section{Discussion}

Ghrelin was discovered as a hormone related to $\mathrm{GH}$ secretion. With advancing gestational age, the placental production of GH is elevated (22). We also found correlation between placental weight and GH levels of neonates. Data available are not consistent; association among circulating total ghrelin and the $\mathrm{GH}$ have been reported by some (7) but not by other authors (23). It is generally assumed that the GH-releasing activity of ghrelin is dependent on its acylation in Serine 3 and mediated by the activation of the type 1a GH secretagogue receptor (24). We have measured not only the total ghrelin, but also the acylated ghrelin and have not found a correlation between acylated or total ghrelin and GH concentrations. Others have found the same results which support the hypothesis that ghrelin is not contributing to the high GH concentrations observed during gestation (25).

However, there was a significant correlation between acylated ghrelin levels of neonates and the placental weight. It is contradictory with Yokota et al. (26), who found inverse correlation between the acylated ghrelin in cord blood and placental weight. However, they examined full-term newborns who were not only of the group of adequate-for-gestational age. It is known that the ghrelin levels of small-for-gestational age are greater than those of appropriate-for-gestational age infants (9). Further investigation is needed to show the possible relationship between the placenta and the acylation process of ghrelin.

No correlation was found between maternal and newborn total ghrelin levels by others $(10,11,27)$. Our results were the same, but we found a significant correlation between the fetal and maternal acylated ghrelin levels. It is possible that acylated ghrelin could cross the placenta in human as suggested by Nakahara (28) in rats. The hypothesis that the placenta may play a role in the acylation process is supported in part by the relationship between fetal acylated ghrelin concentration and the placental weight (Table 3).

In addition to its GH-releasing properties, ghrelin appears to be related to regulation of appetite and glucose metabolism (29). It is known that ghrelin secretion is increased by fasting and decreased by food intake, glucose, and insulin in adults (30), and there is a negative association between ghrelin and insulin secretion (31). We found a negative correlation between 


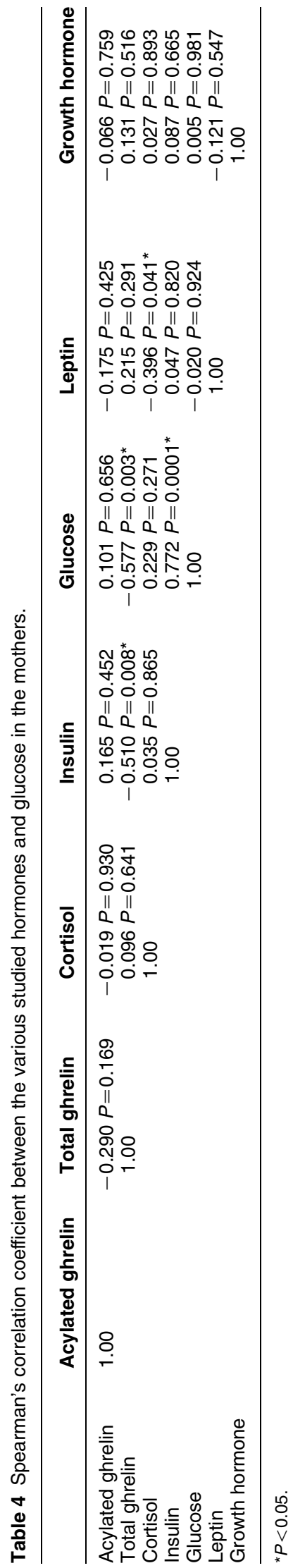

Table 5 Multiple regression model with indices of fetal acylated and maternal total ghrelin as dependent variables.

\begin{tabular}{lcc}
\hline & $\begin{array}{c}\text { Fetal acylated } \\
\text { ghrelin }\end{array}$ & $\begin{array}{c}\text { Maternal total } \\
\text { ghrelin }\end{array}$ \\
\hline Maternal acylated ghrelin & $\begin{array}{l}R^{2} 0.639 \\
\beta=0.733,\end{array}$ & $R^{2} 0.184$ \\
Fetal cortisol & $P=0.0001$ & \\
Maternal glucose & $\beta=0.286$, & \\
& $P=0.038$ & $\beta=-0.467$, \\
& & $P=0.019$ \\
\hline
\end{tabular}

$\beta$ denotes the regression slope, ${ }^{*} P<0.05$.

total ghrelin and glucose, as well as between total ghrelin and insulin concentrations in the mother's blood only. Farquhar et al. found a similar relationship between cord plasma ghrelin and glucose concentrations (17). However, in our experiment, the mothers with known gestational diabetes were excluded, in contrast to referred authors, where the prevalence of maternal diabetes was considerable.

When injected peripherally, ghrelin increases and leptin decreases food intake, suggesting that both peptides are part of a common regulatory loop and leptin contributes to the regulation of ghrelin (32). Leptin is detectable in cord blood from early in the second trimester (33), and circulating levels of cord blood leptin are positively correlated with birth weight and cord plasma insulin level in full-term newborns (34). These results seem to be inconsistent with our findings, because we have not found any correlation with cord blood leptin. The discrepancy may be explained by gestational age, because more than $98 \%$ of leptin secreted by the placenta goes to the maternal side, presumably the fetal leptin is being produced by fetal adipose or other tissues (35). A number of studies have shown that there is a sexual dimorphism in plasma leptin concentrations during the later period of life (36). During the examination period, the concentration of leptin in the cord blood was very low, and we did not see significant differences between male and female infants (data are not shown).

The multiple regression model shows a relationship between the fetal cortisol and fetal acylated ghrelin concentration. We have measured the maternal and fetal plasma cortisol levels in parallel and the results were consistent with others (37); the maternal plasma cortisol levels were ten times higher than fetal plasma cortisol and there was a significant linear correlation between them (Fig. 1). The limitation of our study is the fact that all mothers received betamethasone. The prenatal betamethasone administration to mothers has been shown to result in similar betamethasone concentrations in maternal and fetal serum, because betamethasone is a poor substrate for 11 $\beta$-hydroxysteroid dehydrogenase- 2 , which converts cortisol to inactive cortisone (38). It is known that 
prenatal maternal betamethasone therapy suppresses the cortisol levels within 1 week of betamethasone treatment, as long as the synthetic glucocorticoid remains in circulation (39). It is known that synthetic glucocorticoids have genomic potencies 25 times that of cortisol (40), but there are limited data about their nongenomic potencies. It is revealed from the kinetic studies with steroid receptors located on plasma membranes that cortisol has higher affinity than dexamethasone or betamethasone to plasma membrane receptors (41). This supports the hypothesis that there is no close relationship between the efficiency of non-genomic and classical genomic responses of different glucocorticoids. Our results show a positive correlation between fetal cortisol and acylated ghrelin, and it suggests the possibility that the cortisol may be involved in the acylation process of ghrelin through the membraneinitiated, rapid, non-genomic action.

Several new findings are reported in the present study. These data provide first evidence that in premature newborns umbilical cord acylated ghrelin concentrations are lower than in maternal blood, and the fetal acylated ghrelin correlate with maternal acylated ghrelin and the fetal cortisol. The physiological role of ghrelin during pregnancy remains to be clarified, but it may be related to the degree of acylation. The correlation of the fetal acylated ghrelin with the placental weight, supports the hypothesis that the placenta may play a role in the acylation process and may be partly affected by cortisol.

\section{Acknowledgements}

This study was supported by OTKA T-046695, Hungary.

\section{References}

1 Kojima M, Hosoda $H$, Date $Y$, Nakazato M, Matsuo H \& Kangawa K. Ghrelin is a growth-hormone-releasing acylated peptide from stomach. Nature $1999 \mathbf{4 0 2} 656-660$.

2 Hosoda H, Doi K, Nagaya N, Okumura H, Nagakawa E, Enomoto M, Ono F \& Kangawa K. Optimum collection and storage condition for ghrelin measurements: octanoyl modification of ghrelin is rapidly hydrolyzed to desacyl ghrelin in blood samples. Clinical Chemistry 200450 1077-1080.

3 Broglio F, Gottero C, Prodam F, Gauna C, Muccioli G, Papotti M, Abribat T, Van Der Lely AJ \& Ghigo E. Non-acylated ghrelin counteracts the metabolic but not the neuroendocrine response to acylated ghrelin in humans. Journal of Clinical Endocrinology and Metabolism 200489 3062-3065.

4 Broglio F, Arvat E, Benso A, Gottero C, Muccioli G, Papotti M, Van Der Lely AJ, Deghenghi R \& Ghigo E. Ghrelin, a natural GH secretagogue produced by the stomach, induces hyperglycemia and reduces insulin secretion in humans. Journal of Clinical Endocrinology and Metabolism 200186 5083-5086.

5 Ariyasu H, Takaya K, Tagami T, Ogawa Y, Hosoda K, Akamizu T, Suda M, Koh T, Natsui K, Toyooka S, Shirakami G, Usui T, Shimatsu A, Doi K, Hosoda H \& Kojima M. Stomach is a major source of circulating ghrelin and feeding state determines plasma ghrelin-like immunoreactivity levels. Journal of Clinical Endocrinology and Metabolism 200186 4753-4758.

6 Gualillo O, Caminos JE, Blanco M, Garcia-Caballero T, Kojima M, Kangawa K, Dieguez C \& Casanueva FF. Ghrelin, a novel placentalderived hormone. Endocrinology 2001142 788-794.

7 Chanoine JP, Yeung LPK, Wong ACK \& Birmingham CL. Immunoreactive ghrelin in human cord blood: relation to anthropometry, leptin, and growth hormone. Journal of Pediatric Gastroenterology and Nutrition 200235 282-286.

8 Rindi G, Necchi V, Savio A, Torsello A, Zoli M, Locatelli V, Raimondo F, Cocchi D \& Solcia E. Characterisation of gastric ghrelin cells in man and other mammals: studies in adult and fetal tissues. Histochemistry and Cell Biology $2002117511-519$.

9 Önal EE, Cinaz P, Alalay Y, Türkyilcz C, Bideci A, Aktürk A, Okumus N, Ünal S, Koc E \& Ergenekon E. Umbilical cord ghrelin concentrations in small- and appropriate-for-gestational age newborn infants: relationship to anthropometric markers. Journal of Endocrinology 2004180 267-271.

10 Cortelazzi D, Cappiello V, Morpurgo PS, Ronzoni S, Nobile De Santis MS, Certin I, Beck- Peccoz P \& Spada A. Circulating levels of ghrelin in human fetuses. European Journal of Endocrinology 2003 149 111-116.

11 Bellone S, Rapa A, Vivenza D, Vercellotti A, Petri A, Radetti G, Bellone J, Broglio F, Chigo A \& Bona G. Circulating ghrelin levels in the newborn are positively associated with gestational age. Clinical Endocrinology $200460613-617$.

12 Chanoine JB. Ghrelin in growth and development. Hormone Research 200563 129-138.

13 Wollmann HA. Growth hormone and growth factors during perinatal life. Hormone Research 200053 50-54.

14 Shiiya T, Nakazato M, Mizuta M, Date Y, Mondal MS, Tanaka M, Nozoe S, Hosoda H, Kangawa K \& Matsukura S. Plasma ghrelin levels in lean and obese humans and the effect of glucose on ghrelin secretion. Journal of Clinical Endocrinology and Metabolism 200287 240-244.

15 Marzullo P, Verti B, Savia G, Walker GE, Guzzaloni G, Tagliaferi M, DiBlasio A \& Linzzi A. The relationship between active ghrelin levels and human obesity involves alterations in resting energy expenditure. Journal of Clinical Endocrinology and Metabolism 2004 89 936-939.

16 Tschöp M, Weyer C, Tataranni PA, Devanarayan V, Ravussin E \& Heiman ML. Circulating ghrelin levels are decreased in human obesity. Diabetes 200150 707-709.

17 Farquhar J, Heiman M, Wong ACK, Wach R, Chessex P \& Chanoine JP. Elevated umbilical cord ghrelin concentrations in small for gestational age neonates. Journal of Clinical Endocrinology and Metabolism $2003 \mathbf{8 8} 4324-4327$.

18 Otto B, Cuntz U, Fruehauf E, Wawarta R, Folwaczny C, Riepl RL, Heiman ML, Lehnert P, Fichter M \& Tschöp M. Weight gain decreases elevated plasma ghrelin concentration of patients with anorexia nervosa. European Journal of Endocrinology 2001145 669-673.

19 Otto B, Tschöp M, Heldwein W, Pfeiffer AFH \& Diederich S. Endogenous and exogenous glucocorticoids decrease plasma ghrelin in humans. European Journal of Endocrinology 2004151 113-117.

20 Espelund U, Hansen TK, Hojlund K, Beck-Nielsen H, Clausen JT, Hansen BS, Orskov H, Jorgensen JOL \& Frystyk J. Fasting unmasks a strong inverse association between ghrelin and cortisol in serum: studies in obese and normal-wright subjects. Journal of Clinical Endocrinology and Metabolism $200590741-746$.

21 Lányi É, Csernus K, Erhardt É, Tóth K, Urbán B, Lénárd L \& Molnár D. Plasma levels of acylated ghelin during an oral glucose tolerance test in obese children. Journal of Endocrinological Investigation 200730 133-137.

22 Mirlesse V, Frankenne F, Alsat E, Poncelet M, Hennen G \& EvainBrion D. Placental growth hormone levels in normal pregnancy and in pregnancies with intrauterine growth retardation. Pediatric Research 199334 439-443. 
23 Kitamura S, Yokota I, Hosoda H, Kotani Y, Matsuda J, Naito E, Ito M, Kangawa K \& Kuroda Y. Ghrelin concentration in cord and neonatal blood:relation to fetal growth and energy balance. Journal of Clinical Endocrinology and Metabolism 200388 5473-5477.

24 Muccioli G, Tschop M, Papotti M, Deghenghi R, Heiman M \& Ghigo E. Neuroendocrine and peripheral activities of ghrelin: implications in metabolism and obesity. European Journal of Pharmacology $2002 \mathbf{4 4 0} 235-254$.

25 Pirazzoli P, Lanari M, Zucchini S, Gennari M, Pagotto U, de Iasio R, Pasquali R, Cassio A, Cicognani A \& Cacciari E. Active and total ghrelin concentrations in the newborn. Journal of Pediatric Endocrinology and Metabolism 200518 379-384.

26 Yokota I, Kitamura S, Hosoda H, Kotani Y \& Kangawa K. Concentration of the $n$-octanoylated active form of ghrelin in fetal and neonatal circulation. Endocrine Journal 200552 271-276.

27 Fuglsang J, Sandager P, Mellert N, Fiskert S, Frystyk J \& Ovesen P. Peripartum maternal and foetal ghrelin, growth hormones, IGFs and insulin interrelations. Clinical Endocrinology $2006 \mathbf{6 4}$ 502-509.

28 Nakahara K, Nakagawa M, Baba Y, Sato M, Toshinai K, Date Y, Nakazato M, Kojima M, Miyazato M, Kaiya $H$, Hosoda $H$, Kangawa K \& Murakami N. Maternal ghrelin plays an important role in rat fetal development during pregnancy. Endocrinology 2006147 1333-1342.

29 Nakazato M, Murakami N, Date Y, Kojima M, Matsuo H, Kangawa K \& Matsukura S. A role for ghrelin int he central regulation o feeding. Nature $2001 \mathbf{4 0 9} 194-198$.

30 Nakagawa E, Nagaya N, Okumura H, Enomoto M, Oya H, Ono F, Hosoda H, Kojima M \& Kangawa K. Hyperglycaemia suppresses the secretion of ghrelin, a novel growth-hormone-releasing peptide: responses to the intravenous and oral administration of glucose. Clinical Science 2002103 325-328.

31 Haqq AM, Farooqi S, O'rahilly S, Stadler DD, Rosenfeld RG, Pratt KL, LaFranchi SH \& Purnell J. Serum ghrelin levels are inversely correlated with body mass index, age, and insulin concentrations in normal children and are markedly increased in Prader-Willi syndrome. Journal of Clinical Endocrinology and Metabolism $2003 \mathbf{8 8} 174-178$.

32 Geary N. Endocrine controls of eating: CCK, leptin, and ghrelin. Physiology and Behavior 200481 719-733.
33 Geary M, Herschkovitz R, Prongle PJ, Rodeck CH \& Hindmarsh PC. Ontogeny of serum leptin concentrations in the human. Clinical Endocrinology 199951 189-192.

34 Tsai PJ, Yu CH, Hsu SP, Lee YH, Chiou CH, Hsu YW, Ho SC \& Chu $\mathrm{CH}$. Cord plasma concentrations of adiponectin and leptin in healthy term neonates: positive correlation with birthweight and neonatal adiposity. Clinical Endocrinology 200461 88-93.

35 Linnemann K, Malek A, Sager R, Blum WF, Schneider H \& Fusch C. Leptin production and release in the dually in vitro perfused human placenta. Journal of Clinical Endocrinology and Metabolism $2000 \mathbf{8 5}$ 4298-4301.

36 Kennedy A, Gettys TW, Watson P, Wallace P, Ganaway E, Pau Q \& Garvey WT. The metabolic significance of leptin in humans: gender-based differences in relationship to adiposity, insulin sensitivity, and energy expenditure. Journal of Clinical Endocrinology and Metabolism 199782 1293-1300.

37 Cameron RA, Fisk NM \& Glover V. Fetal exposure to maternal cortisol. Lancet 1998352 707-708.

38 Anderson ABM, Gennser G, Jeremy JY, Ohrlander S, Sayers L \& Turnbull AC. Placental transfer and metabolism of betamethasone in human pregnancy. Obstetrics and Gynecology $1977 \mathbf{4 9}$ 471-474.

39 Marioni E, Korebits C, DiIorio R, Cosmi EU \& Challis JR. Effect of betamethasone in vivo on placental corticotropin-releasing hormone in human pregnancy. American Journal of Obstetrics and Gynecology $1998 \mathbf{1 7 8} 770-778$.

40 Jobe AH \& Soll RF. Choice and dose of corticosteroid for antenatal treatments. American Journal of Obstetrics and Gynecology 2004 $190878-881$.

41 Daufeldt S, Klein R, Wildt L \& Alléra A. Membrane initiated steroid signalling (MISS): computational, in vitro and in vivo evidence for a plasma membrane protein initially involved in genomic steroid hormone effects. Molecular and Cellular Endocrinology 2006246 42-52.

Received 27 September 2007

Accepted 17 October 2007 